\title{
Outdoor Thermal Environments and Activities in Open Space: An Experiment Study in Humid Subtropical Climates
}

\author{
Jianxiang Huang ${ }^{1}$, Chaobin Zhou ${ }^{2}$, Yanbin Zhuo ${ }^{3}$, Luyi Xu ${ }^{3}$, Yi Jiang ${ }^{4}$ \\ ${ }^{1}$ Department of Urban Planning and Design, the University of Hong Kong, Pokfulam Road, \\ Hong Kong SAR, China \\ ${ }^{2}$ Vanke Co., Ltd. Chengdu Regional Headquarters, Chengdu, China \\ ${ }^{3}$ The Built Environment Group Ltd., Tianjin, China \\ ${ }^{4}$ The XIN Center, Tsinghua University, Yejing Building, Tsinghua University, Beijing, China \\ *Corresponding email: jxhuang@hku.hk
}

Keywords: Outdoor Thermal Environment; Open Space; Outdoor Activities; Humid Subtropical Climates; Behavioral Responses by Age, Gender \& Activity Types; Optimum Thermal Environment

Abstract: (250)

The outdoor thermal environment correlates with occupant behaviors in open spaces. The appropriate range of thermal environment that is conducive to outdoor activities, however, remains inadequately defined. Existing studies fail to characterize the behavioral responses to thermal environments in important dimensions including activity types, age or gender. We conducted field studies on six open spaces in Wuhan, China, a city with humid subtropical climate and ideal for this research. Data based on field observations, questionnaires, and measurement were collected under a variety of weather conditions over 4 years. We renovated a playground by adding shading shelters and vegetation cover to reduce summertime heat stress. On-site thermal environment were assessed using the Universal Thermal Climate Index (UTCI). Findings are as following: the outdoor thermal environment is a strong predictor of mean attendance over a period of time, but not spontaneous occupancy at a specific time or space; the Optimum Thermal Environment (OTE), defined as the range in which an open space is wellattended (attendance above 90\% of peak value), is more consistent than the self-reported Thermal Acceptable Range (TAR) in this study. Behavioral responses to thermal environment differ by gender, age, and types of activities. The experiment confirmed the causality between outdoor thermal environment and activities: the renovated playground attracted $80 \%$ more occupants in summer; people stayed longer, reported less heat stress, and interacted with each other more often. Results remained significant after controlling for weather, air quality, daily and weekly routines. Findings had implications for the design of open spaces. 


\section{Introduction}

The outdoor thermal environment, e.g. sunlight, wind, temperature, and humidity, correlated with our behaviors in open spaces. Studies found that the sun/shade patterns over benches is an important quality of outdoor spaces (Gehl 1987), and people preferred to sit under the sun in New York's Seagram Plaza (Whyte 1980). In statistical terms, parameters of the thermal environment explained $50 \%$ of the variance in attendance in Gothenburg, Sweden (Eliasson et al. 2007) , 12\% in Montreal, Canada (de Montigny et al. 2012), or 11\% in San Francisco, USA (Zacharias et al. 2001) (Zacharias 2004). This correlation has important implications for urban planning and design. The popularity of open spaces is a measure of success in place-making (Carmona et al. 2003).Outdoor activities bring social, health, and environmental benefits (Égerházi et al. 2013). Time spent outdoors can effectively reduce the building energy consumed on air conditioning and lighting (Niu et al. 2015). There is a growing consensus that the design of open spaces should be more sensitive towards the outdoor thermal environment (Nicolopoulou et al., 2003) (Chen \& Ng 2012) (Eliasson et al. 2007).

Three weakness in existing literature need to be addressed: first, the thermal environment that is conducive to outdoor activities is inadequately defined. Unlike in the indoor environment where acceptable thermal conditions were reasonably well-established (ASHRAE 2013), acceptable conditions in an outdoor environment are in disputes. Matzarakis et al. suggested that the comfortable/neutral outdoor thermal environments was $18-23^{\circ} \mathrm{C}$ measured in Physiological Equivalent Temperature (PET), a biometerological index (Matzarakis \& Mayer 1996); studies suggested $21.3-28.5^{\circ} \mathrm{C}$ in PET to be acceptable in Taiwan (Lin 2009), or 26.3-31. $7^{\circ} \mathrm{C}$ in Operative Temperature to be acceptable by Singaporeans (Yang et al. 2013). The inconsistencies were credited to factors including adaptation (Nikolopoulou \& Lykoudis 2006), psychological and transient effects (Eliasson et al. 2007), or people seeking thermal delight (Heschong 1979) and alliesthesia (Parkinson \& de Dear 2015). These factors were yet to be further clarified to support design practices.

Second, existing studies failed to characterize the behavioral impact of outdoor thermal environment by activity types, age or gender. The elderly's tolerance towards thermal extremes are found to be limited (Blatteis 2012), and children tend to be disproportionately affected by heat exposure in outdoor playground (Vanos 2015). Specific knowledge in these areas are helpful to design specialized open spaces such as senior fitness corners (Leisure and Cultural Services Department 2006), children's playground, sports field, or multi-general spaces.

Third, the causal evidences are weak between outdoor thermal environments and behavioral outcomes. Existing studies relied mostly on observational methods, making them vulnerable to time and site-specific confounders that were uncontrolled for. Observations can be easily skewed in popular open spaces by groups of tourists who prioritize sight-seeing over thermal stress. The correlational evidences, although confirmed by a growing body of literature, fell short of the 'gold standard' of those from a controlled experiment. 
In response to the above weaknesses, we conducted a unique experiment study in Wuhan, China with humid subtropical climate. Our purposes are to: 1) quantify the optimum thermal environments that are conducive to outdoor activities, 2) characterize behavioral responses to thermal environment by activity types, age, and gender, 3 ) provide causal evidences on the behavioral impact of outdoor thermal environment via a controlled experiment. We studied 6 open spaces in a residential community using observations, questionnaire, and measurement. Among the 6 sites, a playground was renovated by adding shading shelters, vegetation cover, and high-albedo paving. We recorded attendance, activity types, and occupant profiles before and after the experiment on the playground and 5 other sites (control group). Field studies were conducted under a variety of weather conditions on 132 days during 4 years. Our dataset, consisted of 23,164 individual counts and 1460 effective questionnaire responses, is among the largest in existing studies.

This work contributes to research literature in the following aspects: 1) we described the statistical correlations between outdoor thermal environment and behavioral patterns under Humid Subtropical Climates; 2) we quantified the behavioral differences by gender, age, and types of activities towards various outdoor thermal environments; 3) data from controlled experiments provided causal evidence on the impact of outdoor thermal environments on activities.

\section{Methodology}

\subsection{Climate \& Sites}

Our study was conducted in Wuhan, a city of 10 million population in central China $\left(30^{\circ} 35^{\prime} \mathrm{N}\right.$, $114^{\circ} 17^{\prime} \mathrm{E}$, altitude $37 \mathrm{~m}$ ). Wuhan's humid subtropical climate provides a wide range of outdoor thermal environments (Fig. 1), which is ideal for the study. The hot season stretches from June to September, earning the city a nickname "the furnace" (火炉) in popular culture. The cool season occurs between December and March of the next year with a mean air temperature of $6.5^{\circ} \mathrm{C}$. The rests are moderate seasons with the mean air temperature of $17^{\circ} \mathrm{C}$. The relative humidity remains high between $74 \%$ and $80 \%$ all year round.

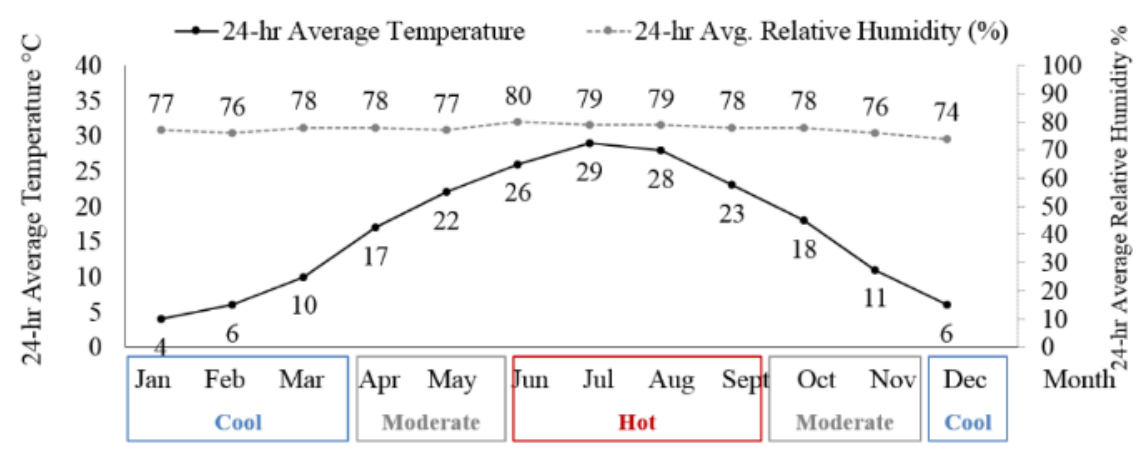

Fig. 1. Monthly temperature and humidity in Wuhan. Data source: China Meteorological Administration, Climate data for Wuhan (1971-2000) 
We studied 6 open spaces located within 5-mins walk from each other. The microclimate conditions on the 6 sites differed considerably due to distinct paving materials, vegetation cover, and the layout of nearby buildings. For instance, the playground was constantly exposed to directly sunlight during the day. It was an open field with a sandpit, a playhouse, and other game facilities at the beginning of the study. The Shangdong (SD) Square was a shaded corridor flanked on the east and west sides by high-rise residential towers; the buildings also accelerated ground level wind, making the SD square a cool and windy place. The Tree Plaza was covered by generous tree canopies, while the Sunken Plaza nearby features concrete paving. The location and site configurations for the 6 open spaces were illustrated in Fig. 2.

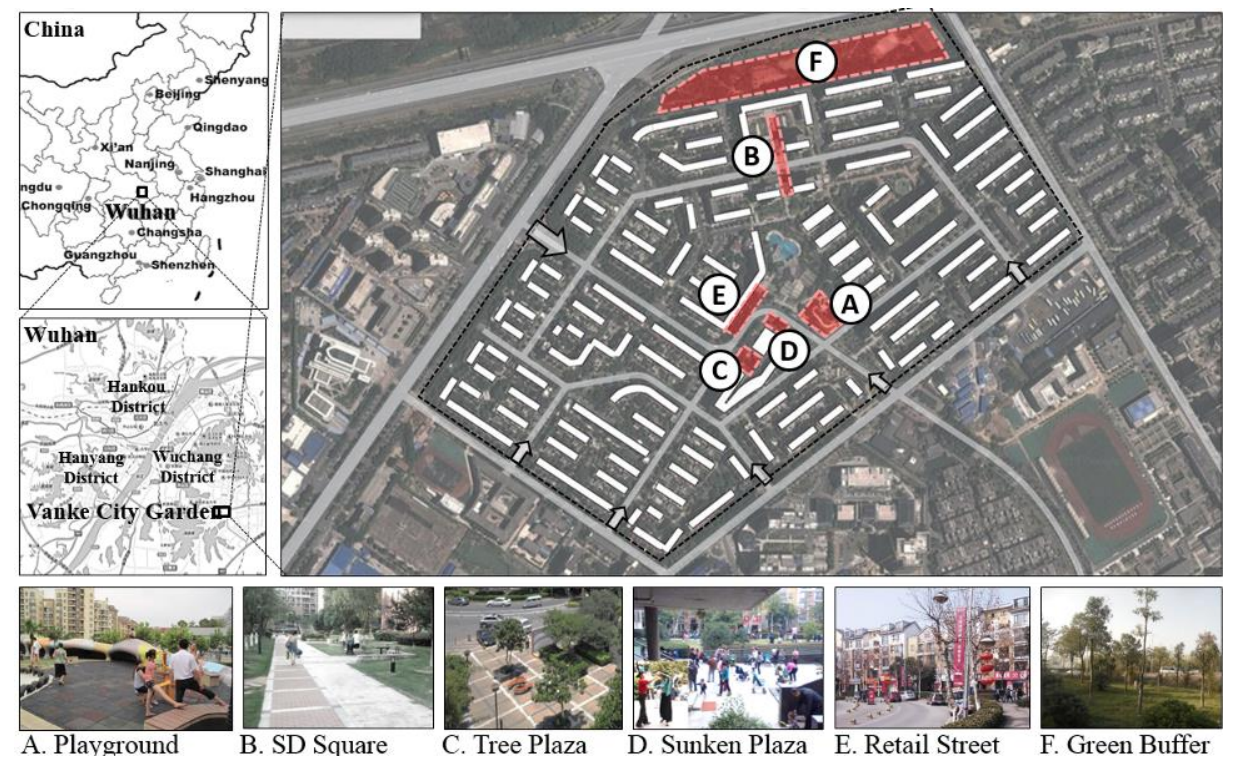

Fig. 2. Study site locations and site configurations

In response to uncertainties associated with an openly accessible space, we chose the study sites to be within the Vanke City Garden (VCG), a semi-enclosed residential community surrounded by fences and gates. Occupants of the 6 study sites are mostly residents of the VCG and our observations are less likely to be skewed by tourists and external visitors. Data provided by the Property Management Office showed that VCG is a mini city in itself, consisted of 4000 uppermiddle income families (11,000 people) and covering an area of 40 hectares. It was developed between the year 2003 and 2008 and became full occupied before our study starts.

\subsection{Field Studies}

The field studies consisted of observations, questionnaire, and measurement on the 6 open spaces. One researcher physically presented in the study sites and recorded overall attendance as well as attendance breakdown by age, gender, and activity types. We recorded 4 age groups Infants (0-2), children (3-17), young adults (18-55) and the elderlies (55+). 12 types of activities were recorded and ranked from Light to Intense by the Metabolic Equivalence of Task (MET) listed by the World Health Organization (World Health Organization 2010) (Table 1). A questionnaire was distributed with questions on age, gender, clothing conditions, and behavioral preferences. We 
also asked questions on the duration of stay, self-reported thermal sensation (7-point ASHRAE scale), thermal comfort rating ("Unacceptable", "Acceptable" and "Comfortable"). The questionnaire used in the field study was included in Appendix 1. The human-subject study protocol was approved by the University of Hong Kong Human Research Ethics Committee for Non-Clinical Faculties (HRECNCF).

Table 1 Recorded activity types ranked by Metabolic Equivalent of Task (MET)

\begin{tabular}{llc}
$\#$ & Activity Types & $\begin{array}{c}\text { Physical Activities by } \\
\text { Level of Intensity }\end{array}$ \\
\hline 1 & Rest (sit) & Light Activity \\
2 & Chess \& Board Games & $(1.1-1.9$ MET) \\
3 & Conversation (sit) & \\
4 & Babysitting (sit) & Moderate Activity \\
5 & Picnic & $(2.0-2.9$ MET) \\
\hline 6 & Conversation (stand) & \\
7 & Babysitting (stand) & \\
8 & Stroll & Intense Activity \\
\hline 9 & Dance & $(3.0+$ MET) \\
10 & Children Play & \\
11 & Exercise & \\
12 & Others (e.g.Tai-Chi or Qi Gong) & \\
\hline
\end{tabular}

Table 2 summarized the field study schedule on 132 days between August 2011 and November 2014. A typical daily session cover 7:00 -12:00 in the morning and 15:00 - 21:00 in the evening. Noon time between 12:00 and 15:00 were excluded in our study because attendance were low due to lunch break and the mid-day nap. The study schedule covers all seasons, weekdays, weekends, holidays, under sunny, cloudy, or windy weather. Precipitation days were excluded because few outdoor activities were visible during the rain or snow.

Table 2 Field Study Schedule

\begin{tabular}{|c|c|c|c|c|c|}
\hline Year & Mon & Day* & Hour & Observation & Questionnaire \\
\hline \multirow[t]{5}{*}{2011} & Aug & $\begin{array}{l}9,11,12,13,15,16,17,18,19,20,21, \\
22,23,24,25,26,27,28,29,30\end{array}$ & 7:00-12:00 \& 15:00-20:00 & 449 & 243 \\
\hline & Sept & $1,6,7,8,12,18,22,23,24,28$ & 8:00-12:00 \& 14:00-20:00 & 107 & 137 \\
\hline & Oct & $3,8,13,14,16,22,27,29$ & $8: 00-12: 00 \&$ 15:00-18:00 & 90 & 61 \\
\hline & Nov & $4,8,10,13,18,21,25,27$ & $8: 00-12: 00 \&$ 15:00-18:00 & 85 & 55 \\
\hline & Dec & $4,9,13,18,19$ & 8:00-12:00 \& 15:00-18:00 & 53 & 0 \\
\hline \multirow[t]{6}{*}{2012} & Feb & 26 & $15: 00-17: 00 * *$ & 10 & 0 \\
\hline & Mar & 16 & $10: 00-11: 00 * *$ & 6 & 0 \\
\hline & Apr & $1,8,11,16,21,25,30$ & 8:00-11:00 \& 15:00-20:00 & 81 & 0 \\
\hline & May & $7,11,20,22,27$ & $8: 00-11: 00 \&$ 15:00-18:00 & 58 & 54 \\
\hline & Jun & $3,9,14$ & $8: 00-11: 00 \&$ 15:00-19:00 & 47 & 79 \\
\hline & Jul & $2,4,7,10,12,15,17$ & 8:00-11:00 \& 16:00-19:00 & 0 & 123 \\
\hline \multicolumn{6}{|c|}{ Aug. $2012-$ Apr.2013 Renovation of the Playground (Experiment) } \\
\hline \multirow[t]{4}{*}{2013} & May & $9,12,13,19,22,23,28,31$ & 7:00-10:00 \& 15:00-18:00 & 65 & 52 \\
\hline & Jun & $3,5,9,14,16,18,21,25,28$ & 7:00-10:00 \& 16:00-19:00 & 72 & 74 \\
\hline & Jul & $2,4,8,9,12,17,19,22,24,26,28,30$ & 7:00-10:00 \& 16:00-19:00 & 92 & 79 \\
\hline & Aug & $1,2,7,9$ & 7:00-10:00 \& 17:00-19:00 & 32 & 16 \\
\hline \multirow[t]{2}{*}{2014} & Sept & $21,23,25,27,30$ & 7:00-12:00 \& 15:00-20:00 & 151 & 103 \\
\hline & Oct & $12,13,15,18,19,20,22,24,25,26$ & $8: 00-11: 00 \& 16: 00-21: 00$ & 127 & 222 \\
\hline
\end{tabular}




\begin{tabular}{llll}
\multicolumn{1}{c}{ Nov $1,2,3,4,8,9,12,15,17$} & $8: 00-12: 00 \& 15: 00-21: 00$ & 87 & 162 \\
\hline Total & 1612 & 1460 \\
\hline *Italic fonts indicate weekend or public holidays & &
\end{tabular}

On-site microclimatic parameters were measured on the Playground and the SD Square, each using a weather station (HOBO) equipped to record solar radiation $(\mathrm{S} \downarrow)$, wind speed $(\mathrm{W})$, air temperature $\left(\mathrm{T}_{\mathrm{a}}\right)$, and relative humidity $(\mathrm{RH})$ (Fig. 3). Municipal weather data were acquired from the meteorological station at the Wuhan Tianhe International Airport, $25 \mathrm{~km}$ away from the study sites. To control for air pollution, we acquired Wuhan's daily mean Air Quality Index (AQI), a composite metrics computed using the level of 6 atmospheric pollutants -- $\mathrm{SO}_{2}, \mathrm{NO}_{2}$, $\mathrm{PM}_{10}, \mathrm{PM}_{2.5}, \mathrm{CO}$, and $\mathrm{O}_{3}$ (MEP, 2014).
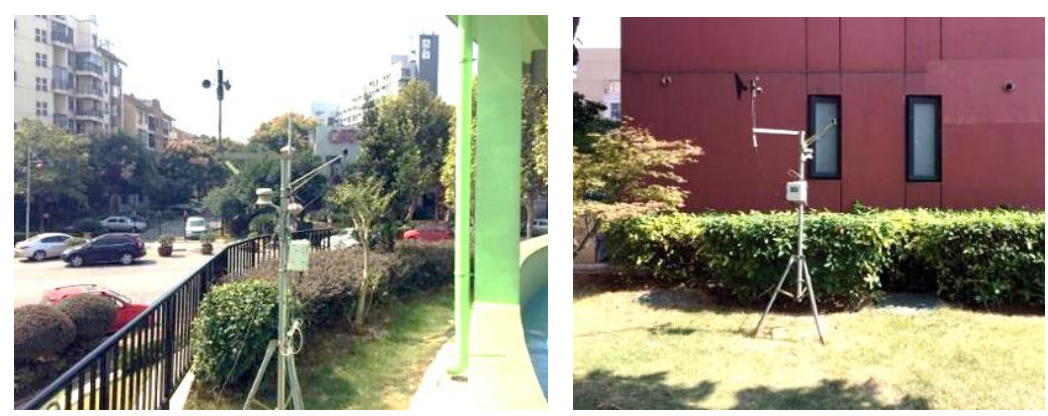

Fig. 3 HOBO weather station installed on the playground (left) and SD Square (right).

\subsection{The Experiment}

We conducted an experiment to renovate the Playground in order to modify the on-site microclimate. An earlier study on the playground identified excessive heat stress in summer and low usage rates (Lai et al. 2014). We built shading shelters of both overhangs and vertical fins on the southern side. Tree canopies and hedgerows were added to increase cooling effect from evapotranspiration. To reduce surface temperature at ground surfaces, we replaced the original black rubber tiles with blue ones of higher albedo; this can reduce the risks of children skins burns or damage (Vanos et al. 2016). Renovation works began in August 2012 and finished in April 2013. Fig. 4 shows the perspective views and plans before and after the renovation. The playground facilities, including the seesaw, climbers, the playhouse, and seating were kept unchanged. 
(a)

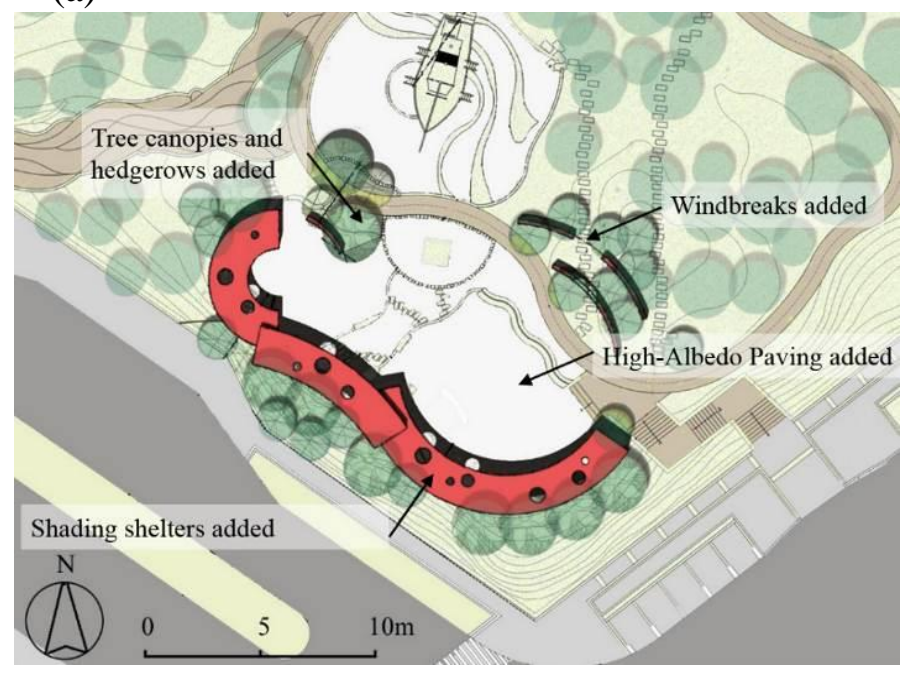

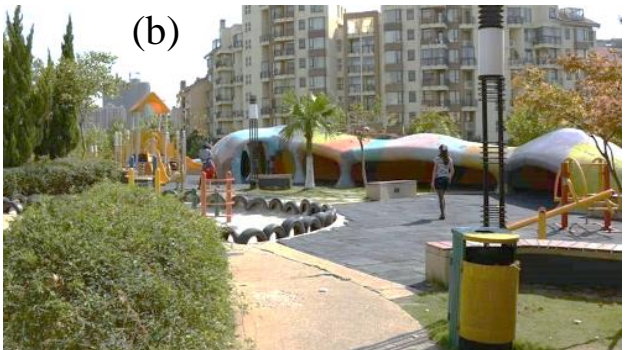

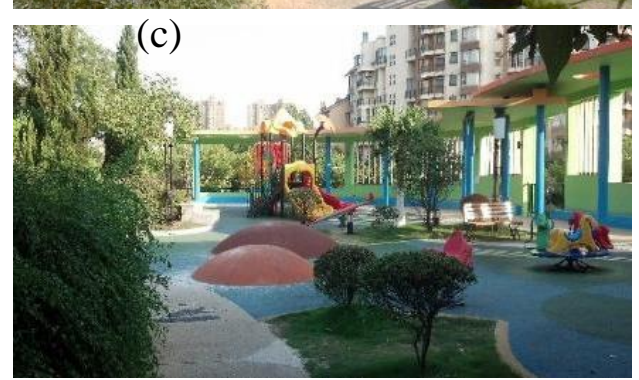

Fig. 4 (a) Renovation plan of the Playground; (b) Playground view before renovation (photo taken Jun.22, 2012); (c) Playground view after renovation (photo taken Aug.2, 2013)

On-site microclimatic data showed that the renovation effectively reduced solar radiation intensity and air temperature on the playground. We cannot directly compare measured meteorological data at the Playground before and after renovation, since the dates and weather differ. Instead, we used the meteorological conditions measured at the SD Square as the benchmark with which data measured on the Playground were compared. We are interested in the differences between the two sites of solar radiation intensity $\left(S_{P}-S_{S D}\right)$ and air temperature $\left(T_{P}-T_{S D}\right)$. Fig. 5 (left) shows $S_{P}-S_{S D}$ was large before renovation on Jul.22 2012. Fig. 5 (right) shows that $S_{P}-S_{S D}$ was significantly reduced after renovation on Aug.2 2013. Fig. 6 (left) shows that $T_{P}-T_{S D}$ was nearly $2{ }^{\circ} \mathrm{C}$ on Jul.22, 2012 before renovation; such difference was reduced to within $1{ }^{\circ} \mathrm{C}$ on Aug. 2013 after renovation (Fig. 6(right))
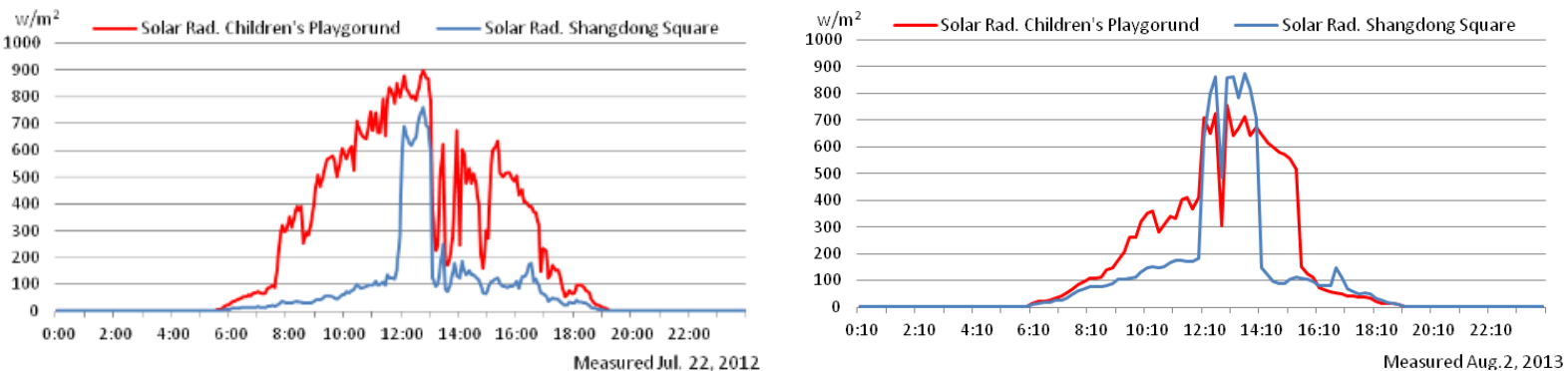

Fig. 5 (left) Solar radiation measured at the Playground and the SD Square before renovation; (right) Solar radiation measured at the Playground and the SD Square after renovation. 

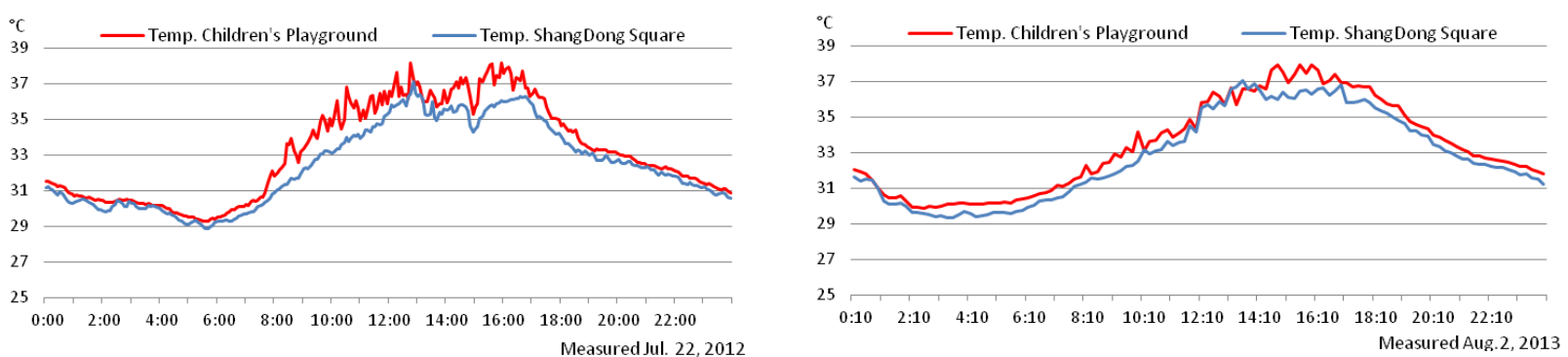

Fig. 6 (left) Air Temperature measured at the Playground and the SD Square before renovation; (right) Air Temperature measured at the Playground and the SD Square after renovation

\subsection{Data Analysis}

The outdoor thermal environment was assessed using the Universal Thermal Climate Index (UTCI) (Jendritzky et al. 2012). Other thermal indices for the outdoor environment include the Standard Effective Temperature (SET*) (ASHRAE 2013), Out_SET (Pickup \& de Dear 2000), the Physiological Equivalent Temperature (PET) (Höppe 1999), and the Operative Temperature (ASHRAE 2013). Compared with other thermal indices, UTCI has advantages in presenting specific climates, weather, and locations (Blazejczyk et al. 2012).

Formula (1) shows the mathematical model of human body heat transfer and thermal regulatory responses, where energy conservation holds for each bodily segment. $\mathrm{M}$ is the metabolic heat gain; $\mathrm{W}$ is the work output; $\mathrm{C} \& \mathrm{R}$ are convective and radiative heat transfer; $E_{s k}, C_{\text {res }}, E_{\text {res }}$ and $S_{s k}$ are heat losses via skin diffusion, dry respiration, latent respiration and sweat secretion.

$\mathrm{M}-\mathrm{W}=\mathrm{q}_{\mathrm{sk}}+\mathrm{q}_{\mathrm{res}}+S=\left(C+R+E_{s k}\right)+\left(C_{r e s}+E_{r e s}\right)+\left(S_{s k}+S_{c r}\right)$

Using on-site measured microclimatic data, we calculated the UTCI equivalent temperature for each site ${ }^{1}$ using a six-order polynomial calculator (Brode \& Wojtach 2010). The concept of the calculator is shown in formula (2), in which UTCI equivalent temperature is a function of sitespecific air temperature $\left(T_{a}\right)$, mean radiant temperature $\left(T_{m r t}\right)$, wind speed $\left(V_{a}\right)$, and water vapor pressure $\left(\mathrm{V}_{\mathrm{p}}\right)$. We computed the mean radiant temperature $\left(\mathrm{T}_{\mathrm{mrt}}\right)$ using the CityComfort+ method, a simulation-based method that takes into account for all channels of radiative exchanges between the thermal environment and a human body (Huang et al. 2014).

$\mathrm{UTCI}=\mathrm{f}\left(\mathrm{T}_{\mathrm{a}} ; \mathrm{T}_{\mathrm{mrt}} ; \mathrm{Va} ; \mathrm{RH}\right)=\mathrm{Ta}+\operatorname{Offset}\left(\mathrm{T}_{\mathrm{a}} ; \mathrm{T}_{\mathrm{mrt}} ; \mathrm{Va} ; \mathrm{RH}\right)$

Statistical analysis were performed on observational and questionnaire data using STATA software. We use multiple regressions to determine the behavioral impact of the renovated playground. The regression model allows us to determine the independent effect of the experiment and controlling for confounders including weather, air pollution, and daily/weekly routines. Formula (3) shows the concept of the regression model. The left-hand variable (Y) is attendance, duration of stay, or self-reported thermal sensation scores; $\beta_{0}$ to $\beta_{7}$ are coefficients

\footnotetext{
${ }^{1}$ On-site measurement was unavailable for the Tree Plaza, Sunken Plaza, Retail Street, and Green Buffer. For these four sites, the municipal meteorological data were used instead.
} 
for right-hand variables: $R$ is the dummy variable for renovation $(1=$ after renovation; $0=$ before renovation); $A_{q}$ is the Air Quality Index, $T_{a-m e t}, R_{m e t}, V_{\text {met }}, R H_{m e t}$ are the air temperature, solar radiation, wind speed, and relative humidity measured from the meteorological station at the Airport. $T_{w e}$ is the dummy variable of workday evening (1/0); $T_{n d}$ is the dummy for nonworkday daytime; $T_{n e}$ is the dummy for non-workday evening. $\mu$ is the residual. Each observation was treated as an independent measurement, since it was obtained at least an hour apart from the next observation on the same site.

$Y=\beta_{0} R+\beta_{1} A_{q}+\beta_{2} T_{a-m e t}+\beta_{3} R_{m e t}+\beta_{4} V_{m e t}+\beta_{5} R H_{m e t}+\beta_{6} T_{w e}+\beta_{6} T_{n d}+\beta_{7} T_{n e}+\mu$

\section{Results and Discussion}

\subsection{Outdoor Thermal Environments and Behaviors in Open Space}

To determine how much attendance correlate with the outdoor thermal environments, we constructed a regression model using UTCI equivalent temperature (on-site measurement data) to predict attendance in open spaces. A quadratic curve instead of a linear one was used because observed attendance declines towards both high and low temperature conditions. Literature suggested that attendance in public spaces are affected by routine tasks (de Montigny et al. 2012). To control for routine factors, we regressed Mean Attendance on Mean UTCI over hourly, daily, weekly, and monthly intervals. Results are shown in Table 3. While measured UTCI explained $3 \%$ of variations of spontaneous attendance, the Hourly Mean UTCI ( $\left.\overline{U T C I}_{\text {hour }}\right)$ explained $8 \%$ of the variations of Hourly Mean Attendance $\left(\bar{A}_{\text {hour }}\right)$; Daily Mean UTCI ( $\left.\overline{U T C I}_{\text {day }}\right)$, Weekly Mean UTCI ( $\left.\overline{U T C I}_{\text {week }}\right)$, and Monthly Mean UTCI ( $\left.\overline{U T C I}_{\text {month }}\right)$ explained $17 \%$ of variations of Daily Mean Attendance $\left(\overline{A_{\text {day }}}\right), 29 \%$ of those of Weekly Mean Attendance $\left(\bar{A}_{\text {week }}\right)$, and $58 \%$ of those of the Monthly Mean Attendance $\left(\bar{A}_{\text {month }}\right)$. The above observations suggested that our model can explain mean behavioral patterns reasonably well, although outdoor thermal environment alone is not a good predictor of spontaneous attendance at a specific time and location.

Table 3. Regression models of Mean Attendance and Mean Thermal Environment over hourly, daily, weekly, and monthly intervals.

\begin{tabular}{lccccc} 
& $\begin{array}{c}\text { Spontaneous } \\
\text { Attendance }\end{array}$ & $\begin{array}{c}\text { Hourly Mean } \\
\left(\bar{A}_{\text {hour }}\right)\end{array}$ & $\begin{array}{c}\text { Daily Mean } \\
\left(\overline{\bar{A}}_{\text {day }}\right)\end{array}$ & $\begin{array}{c}\text { Weekly Mean } \\
\left(\bar{A}_{\text {week }}\right)\end{array}$ & $\begin{array}{c}\text { Monthly Average } \\
\left(\bar{A}_{\text {month }}\right)\end{array}$ \\
\hline & Coef. $(\mathrm{P}>\mathrm{t})$ & Coef. $(\mathrm{P}>\mathrm{t})$ & Coef. $(\mathrm{P}>\mathrm{t})$ & Coef. $(\mathrm{P}>\mathrm{t})$ & Coef. $(\mathrm{P}>\mathrm{t})$ \\
$\mathrm{UTCI}\left({ }^{\circ} \mathrm{C}\right)$ & $1.750\left(0.00^{* * *}\right)$ & $1.825\left(0.00^{* * *}\right)$ & $1.281\left(0.00^{* * *}\right)$ & $1.229\left(0.00^{* * *}\right)$ & $1.069\left(0.00^{* * *}\right)$ \\
$\mathrm{UTCI}^{2}$ & $-0.385\left(0.00^{* * *}\right)$ & $-0.041\left(0.00^{* * *}\right)$ & $-0.032\left(0.00^{* * *}\right)$ & $-0.033\left(0.00^{* * *}\right)$ & $-0.030\left(0.00^{* * *}\right)$ \\
Intercept & $-2.919(0.43)$ & $-3.245(0.49)$ & $3.462(0.47)$ & $4.819(0.32)$ & $7.254(0.06)$ \\
\# of Obs. & 1197 & 309 & 98 & 46 & 17 \\
$\mathrm{R}^{2}$ & 0.030 & 0.083 & 0.168 & 0.290 & 0.583 \\
Root MSE & 15.551 & 9.655 & 5.834 & 4.379 & 2.768 \\
\hline *** 99\% significance level & $* * 95 \%$ significance level * $90 \%$ significance level
\end{tabular}

$* * * 99 \%$ significance level $* * 95 \%$ significance level *90\% significance level 


\subsection{The Optimum Thermal Environment}

To determine what thermal environment is conducive to outdoor activities, we introduced the concept of Optimum Thermal Environment (OTE), the range in which mean attendance exceeds or equal $90 \%$ of its maximum value. The threshold value of $90 \%$ was in reference to ASHRAE standards that the thermal conditions being acceptable to 90\% of the occupants (ASHRAE 2013). As an alternative to the Thermal Acceptable Range (TAR) which relies on subjective voting (Lin 2009), the OTE is based on attendance data -- people voted with their feet. OTE is useful from a practical perspective: attendance is an important measure of success of public open spaces (Carmona et al. 2003); occupant counts are easier to obtain using observations or surveillance camera compared with questionnaire responses.

The calculation of OTE is provided in Fig. 7 as an example. First, we computed the Mean Attendance $\left(\overline{A_{\text {UTCI }} b i n}\right)$ within the bin of 1 degree on UTCI scale. This transformation technique was common in existing literature (Yang et al. 2013; Lin 2009; Cohen et al. 2013; Zacharias et al. 2001). After transformation, we regressed $\overline{A_{\text {UTCI_bln }}}$ on UTCI and UTCI squared ${ }^{2}$. Using coefficients and intercept derived from the above regression model, we constructed a quadratic fitted curve shown in red line in Fig. 7. The curve had a maximum attendance at $22.0^{\circ} \mathrm{C}$ for Humid Subtropical Climates, compared with the Neutral Temperature of $22.7-23.9^{\circ} \mathrm{C}$ found in Mediterranean regions (Cohen et al. 2013) or the Neutral Temperature of $23.7^{\circ} \mathrm{C}$ found in Central Taiwan (Lin 2009). After solving the quadratic fitted equation at attendance $=90 \%$ maximum value, we derived the OTE for Humid Subtropical Climates to be $15.2-28.8^{\circ} \mathrm{C}$, which covers the entire "UTCI thermal comfort zone" of $18-26^{\circ} \mathrm{C}$ (Jendritzky et al. 2012) and extending by $2.8^{\circ} \mathrm{C}$ both into the "moderate heat stress" zone $\left(26-32^{\circ} \mathrm{C}\right)$ and the "no thermal stress" zone $\left(9-18^{\circ} \mathrm{C}\right)$. Occupants of this study tolerated slight heat stress up to $28.8^{\circ} \mathrm{C}$, yet they were less tolerant to cool environments (below $15.2^{\circ} \mathrm{C}$ )

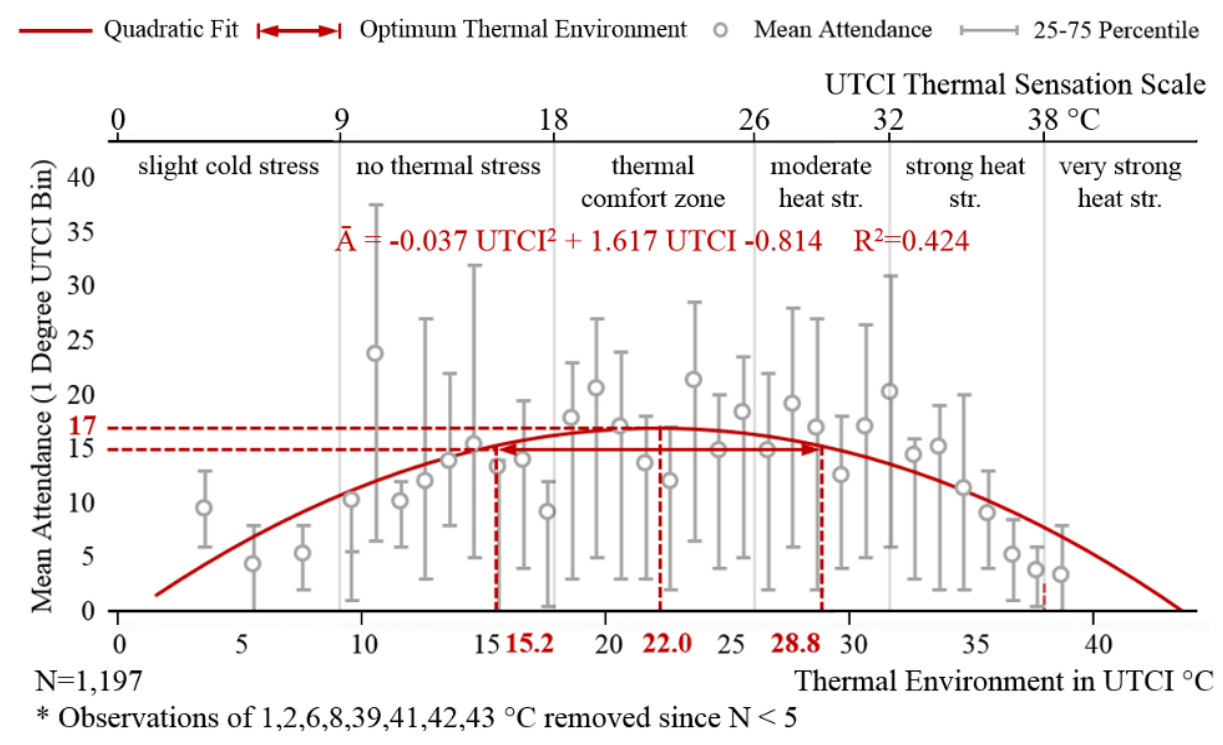

${ }^{2}$ Observations in UTCI bins of $1,2,6,8,39,41,42,43{ }^{\circ} \mathrm{C}$ were removed because $\mathrm{N}<5$. 
Fig. 7 Scatterplot of Mean Attendance (within 1 degree UTCI bin) and outdoor thermal environment measured in UTCI. The Optimum Thermal Environment for outdoor activities in humid subtropical climates is between 15.2 and $28.8^{\circ} \mathrm{C}$

We found that the Thermal Acceptable Range (TAR), a metrics based on subjective voting, was inconsistent and deviated from the UTCI thermal comfort zone of $18-26^{\circ} \mathrm{C}$. Fig. 8 (left) shows the TAR computed using Thermal Acceptability Vote (TAR-TAV) acceptable to $90 \%$ of occupants to be $17.0-33.0{ }^{\circ} \mathrm{C}$. Thermal Acceptability was obtained by asking participants whether they consider the thermal environment "acceptable" (including comfortable) or "unacceptable". The Mean Percentage of Thermal Acceptability (MPTA) was computed for each bin of $1{ }^{\circ} \mathrm{C}$ increment in UTCI. The quadratic fitted curve (red line) was derived by regressing MPTA over UTCI and UTCI ${ }^{2}$. Responses to our questionnaire overstated acceptability in especially hot environments.

Fig. 8 (right) shows the Thermal Acceptable Range calculated using the Thermal Sensation Vote (TAR-TSV) method was $11.1-27.4^{\circ} \mathrm{C}$. The linear fitted curve of Thermal Sensation $=\mathrm{f}$ (UTCI) was shown in the red line. We consider the thermal environment acceptable to occupants if the Thermal Sensation Vote are 'neutral', "slightly warm", or "slightly cool", referring to earlier work by de Dear et al. (de Dear \& Fountain 1994). By solving the above equation for Thermal Sensation $=1$, we derived TAR-TSV to be $11.1-27.4^{\circ} \mathrm{C}$, the range deviates from the UTCI thermal comfort zone of $18-26^{\circ} \mathrm{C}$ and it was inconsistent with the one from TAR-TAV. People seemed to have under-reported their cold sensation in cool environments.
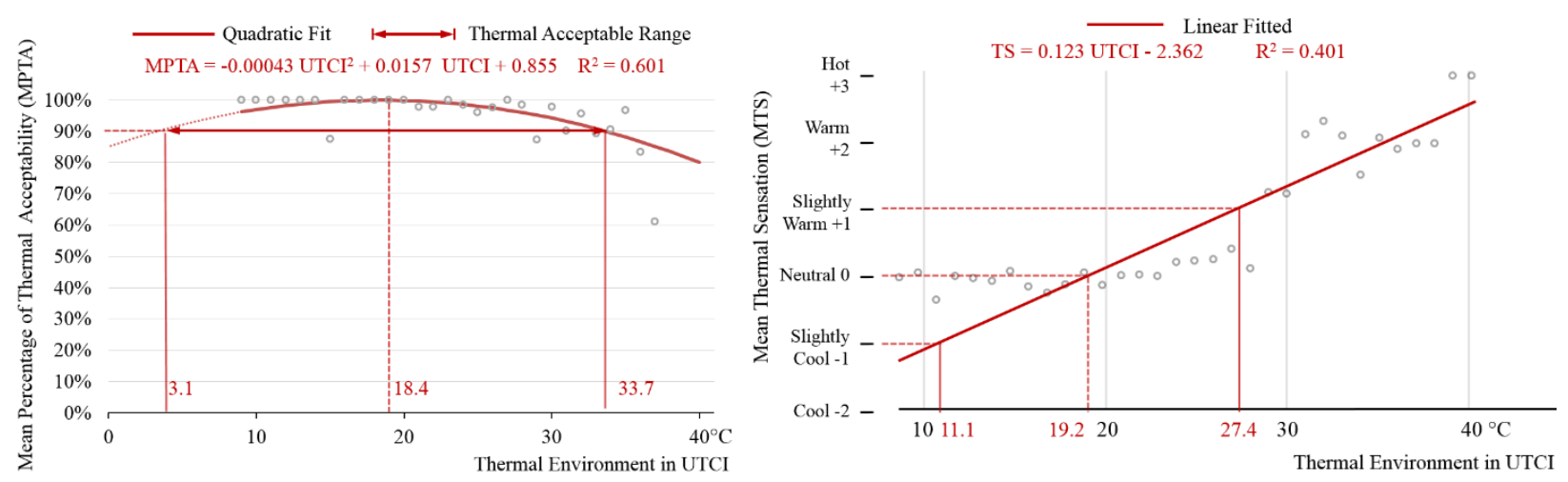

Fig. 8 (Left) Thermal Acceptable Range based on Thermal Acceptability Vote (TAR-TAV); (Right) Thermal Acceptable Range based on Thermal Sensation Vote (TAR-TSV).

\subsection{OTE by Gender, Age, and Types of Activity}

We found significant behavioral differences in response to various thermal environments by gender, age groups, and types of activity. OTE and quadratic fitted curves by gender, age, and types of activity were provided in Error! Reference source not found.. OTE for male (16.5$29.1^{\circ} \mathrm{C}$ ) was higher than it was for female $\left(14.6-27.8^{\circ} \mathrm{C}\right)$. A Chow Test of the quadratic equations for male and female yielded the score $\mathrm{F}=23.75$ with 64 degrees of freedom, meaning the difference between two gender groups was statistically significant. Details of the Chow Test was provided in Appendix 2. 
OTE for the elderly group (55+), young adults (18-54), and children (0-17) were $15.3-28.5^{\circ} \mathrm{C}$, $15.3-28.0^{\circ} \mathrm{C}$, and $14.0-28.3^{\circ} \mathrm{C}$. Seniors were less tolerant of cold stress compared with young adults and children, and the differences were statistically significant: the Chow Test between the elderly and children groups yielded F= 5.349 with 64 degrees of freedom; the Chow Test between the elderly and young adults group yielded the score F=9.523 with 64 degrees of freedom. In both tests we can reject the null hypothesis at the critical value of 0.05 . Details are provided in Appendix 2.

OTE for light, moderate, and intense activities were $15.1-28.5^{\circ} \mathrm{C}, 18.2-30.6^{\circ} \mathrm{C}$, and $9.0-23.9^{\circ} \mathrm{C}$ respectively. Occupants engaged in light activities preferred a thermal environment close to the UTCI comfort zone $\left(18-26^{\circ} \mathrm{C}\right)$; they preferred warmer environments if engaged in moderate activities. People engaged in intense activities preferred cooler environments. Chow Test scores showed that the differences among the three subgroups were statistically significant (Appendix 2). OTE and quadratic fitted equations for all types of activities were provided in Appendix 3.

Table 4 OTE and quadratic fitted curve by gender, age, and types of activity. Mean attendance calculated within 1 degree of UTCI bin.

\begin{tabular}{|c|c|c|c|}
\hline Attendance Breakdown & OTE in UTCI ${ }^{\circ} \mathrm{C}$ & Quadratic Fitted Curve & $\mathrm{R}^{2}$ \\
\hline \multicolumn{4}{|l|}{ By Gender } \\
\hline Male & $16.5-29.1$ & $\overline{A_{\text {UTCI br }}}=-0.011 \mathrm{UTCI}^{2}+0.513 \mathrm{UTCI}-1.354$ & 0.657 \\
\hline Female & $14.6-27.8$ & $\overline{A_{U T C I} b m}=-0.018 \mathrm{UTCI}^{2}+0.750$ UTCI -0.235 & 0.673 \\
\hline \multicolumn{4}{|l|}{ By Age Group } \\
\hline Elderly $(55+)$ & $15.3-28.5$ & $\overline{A_{U T C I \text { bin }}}=-0.017 \mathrm{UTCI}^{2}+0.727$ UTCI -0.805 & 0.620 \\
\hline Young Adults (18-54) & $15.3-28.0$ & $\overline{A_{U T C I} b r n}=-0.012$ UTCI $^{2}+0.535$ UTCI -0.783 & 0.648 \\
\hline Children (0-17) & $14.0-28.3$ & $\overline{A_{\text {UTCI bin }}}=-0.010 \mathrm{UTCI}^{2}+0.405 \mathrm{UTCI}+0.596$ & 0.277 \\
\hline \multicolumn{4}{|l|}{ By Activity Type } \\
\hline Light Activities & $15.1-28.5$ & $\overline{A_{U T C I} b u}=-0.017 \mathrm{UTCI}^{2}+0.724$ UTCI -0.476 & 0.564 \\
\hline Moderate Activities & $18.2-30.6$ & $\overline{A_{U T C I} b u n}=-0.013 \mathrm{UTCI}^{2}+0.650 \mathrm{UTCI}-2.811$ & 0.568 \\
\hline Intense Activities & $9.0-23.9$ & $\overline{A_{U T C I} b l n}=-0.008 \mathrm{UTCI}^{2}+0.258 \mathrm{UTCI}+2.241$ & 0.416 \\
\hline Overall & $15.2-28.8$ & $\frac{A_{U T C I} \text { bin }}{A_{U T C}}=-0.037 \mathrm{UTCI}^{2}+1.617$ UTCI -0.814 & 0.424 \\
\hline
\end{tabular}

The OTE variation by activity types were confirmed by attendance data in hot, moderate, and cool environments (Fig. 9). When exposed to strong heat stress, 17\% of occupants were engaged in intense activities, $31 \%$ moderate, and 52\% light. In a moderate thermal environment, intense activities accounted for $29 \%$ of the total, moderate $27 \%$, and light $44 \%$. When exposed to slight cold stress, the percentage of intense activities rose to $45 \%$, moderate $10 \%$, and light $45 \%$. Changes across the thermal conditions were statistically significant in t-test scores. 


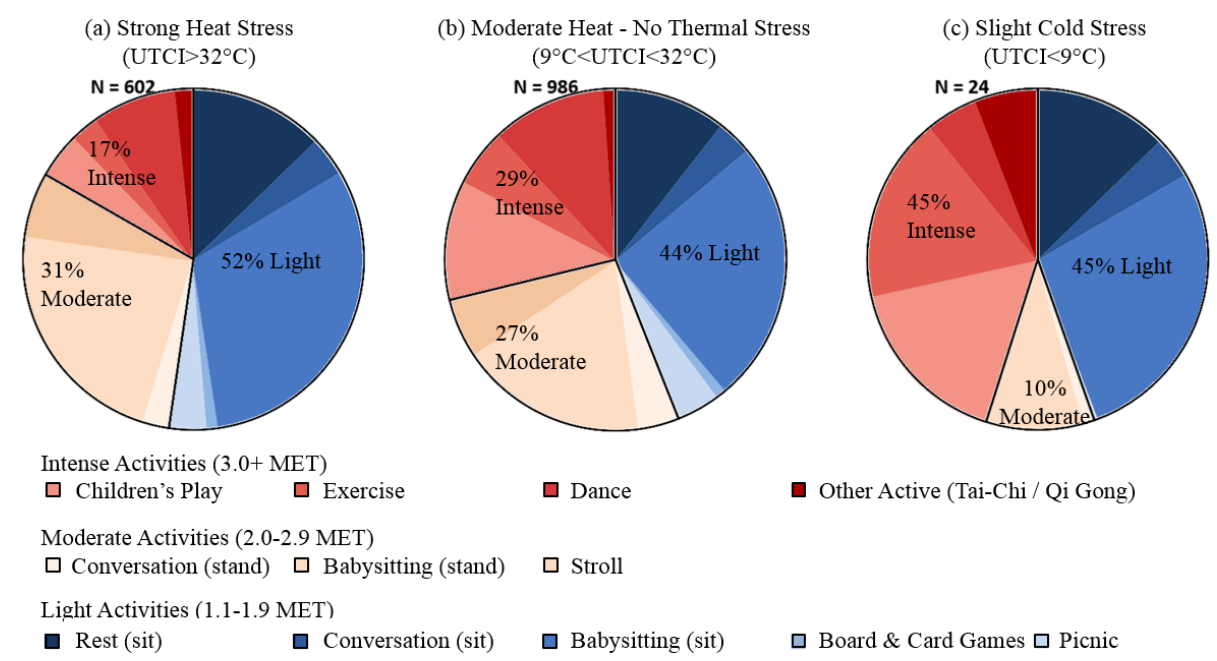

Fig. 9 Attendance breakdown by activity types in hot, moderate and cool environments

\subsection{Behavioral Changes Before \& After Experiment}

The experiment turned the playground into a more attractive, socially interactive, and multigenerational place. Several behavioral changes were observed on the playground after the renovation: 1) increased attendance from especially the elderlies and young adults, 2) longer duration of stay and less reported thermal stress; 3) increased social interactions, 4) more daytime attendance compared with in the early morning or evenings before renovation.

First of all, recorded playground attendance increased by $80 \%$ in hot seasons on average after renovation, and the gains on the playground was at the loss of other sites. Results were significant after controlling for weather, air pollution, and daily/weekly routines. Table 5 shows the regression model for the playground (the experiment group) and other sites (control group) across seasons. The renovated playground experienced an increase in attendance by 12 people $(\mathrm{P}<0.00)$, while the 5 other sites (control group) witnessed a 10 person/site decline in attendance after the experiment $(\mathrm{P}<0.00)$. No increases in attendance were found in moderate and cool seasons. Significant behavioral correlations with weekly/daily routines were found. Compared with the baseline of weekday hours, attendance increased in weekday evenings and during nonworking days. Air temperature and humidity were negatively correlated with attendance. No correlation between behaviors and Air Quality Index were observed on the playground in summer.

Table 5 Regressing attendance on renovation at the Playground and 5 other sites, controlling for daily / weekly routines, and weather.

\begin{tabular}{|c|c|c|c|c|}
\hline & \multicolumn{2}{|c|}{ Hot Season (Jun. - Sept.) } & \multicolumn{2}{|c|}{ Moderate \& Cool Seasons (Oct.-May) } \\
\hline & Playground & 5 Other Sites & Playground & 5 Other Sites \\
\hline & Coef. $(\mathrm{P}>\mathrm{t})$ & Coef. $(\mathrm{P}>\mathrm{t})$ & Coef. $(\mathrm{P}>\mathrm{t})$ & Coef. $(P>t)$ \\
\hline Renovation $($ after $=1 /$ before $=0$ ) & $11.94\left(0.00^{* * *}\right)$ & $-0.97(0.55)$ & $-10.27(0.00 * * *)$ & $-4.00(0.01 * *)$ \\
\hline
\end{tabular}




\begin{tabular}{|c|c|c|c|c|}
\hline Workday evening $(1 / 0)$ & $18.08(0.00 * * *)$ & $15.30(0.00 * * *)$ & $5.40(0.28)$ & $-7.80(0.00 * * *)$ \\
\hline Non-workday day (1/0) & $0.50(0.00 * * *)$ & $-0.94(0.45)$ & $6.31(0.01 * * *)$ & $-1.69(0.25)$ \\
\hline Non-workday evening (1/0) & $27.84(0.00 * * *)$ & $20.11(0.00 * * *)$ & $8.51(0.01 * * *)$ & $0.87(0.78)$ \\
\hline \multicolumn{5}{|l|}{ Meteorological parameters } \\
\hline Air Temp. Met. $\left({ }^{\circ} \mathrm{C}\right)$ & $-1.84(0.00 * * *)$ & $-0.30(0.18)$ & $-0.60(0.03 * *)$ & $0.11(0.35)$ \\
\hline Relative Humid. Met. (\%) & $-0.30(0.02 * *)$ & $0.05(0.53)$ & $-0.36(0.00 * * *)$ & $0.07\left(0.06^{*}\right)$ \\
\hline Solar Rad. Met. (w/m²) & $0.00(0.99)$ & $0.01(0.00 * * *)$ & $0.00(0.55)$ & $0.01(0.15)$ \\
\hline Wind Speed Met. (m/s) & $-1.26(0.10)$ & $-1.00(0.02 * *)$ & $-2.97(0.03 * *)$ & $-0.16(0.85)$ \\
\hline Air Quality Index & $0.03(0.43)$ & $0.05\left(0.06^{*}\right)$ & $0.08(0.01 * * *)$ & $0.03(0.14)$ \\
\hline Intercept & $76.54(0.00 * * *)$ & $15.05(0.18)$ & $61.69(0.00 * * *)$ & $4.21(0.22)$ \\
\hline Number of Observations & 163 & 607 & 129 & 439 \\
\hline $\mathrm{R}^{2}$ & 0.40 & 0.17 & 0.36 & 0.04 \\
\hline Root MSE & 10.78 & 13.70 & 12.76 & 15.68 \\
\hline
\end{tabular}

$* * * 99 \%$ significance level $* * 95 \%$ significance level *90\% significance level

Second, occupants stayed longer on the playground and reported less heat stress after renovation. Table 6 shows results of regressing duration of stay (self-reported) on renovation (binary) after controlling for air quality and weather conditions. Occupants stayed for extra 0.89 hours after renovation $(\mathrm{P}<0.00)$ and reported less heat stress $(\mathrm{P}<0.00)$ in thermal sensation vote $(1.13$ lower in ASHRAE scale). The above results remained significant after controlling for age, gender, and activity types.

Table 6 Regression duration of stay and thermal sensation on renovation at the playground, controlling for air quality, and weather conditions

\begin{tabular}{lcc} 
& $\begin{array}{c}\text { Duration of Stay } \\
\text { Coef. }(\mathrm{P}>\mathrm{t})\end{array}$ & $\begin{array}{c}\text { Thermal Sensation } \\
\text { Coef. }(\mathrm{P}>\mathrm{t})\end{array}$ \\
\hline $\begin{array}{l}\text { Renovation }(\text { after=1/before }=0) \\
\text { Meteorological parameters }\end{array}$ & $0.89\left(0.00^{* * *}\right)$ & $-1.13\left(0.00^{* * *}\right)$ \\
$\quad$ Air Quality Index & $0.002\left(0.00^{* * *}\right)$ & $0.00(0.20)$ \\
Temperature $\left({ }^{\circ} \mathrm{C}\right)$ & $0.001(0.66)$ & $0.06\left(0.00^{* * *}\right)$ \\
Solar Radiation $(\mathrm{w} / \mathrm{m} 2)$ & $0.0003\left(.00^{* * *}\right)$ & $0.00(0.14)$ \\
Wind Speed(m/s) & $0.05\left(0.00^{* * *}\right)$ & $0.10(0.01 * *)$ \\
Relative Humidity $(\%)$ & $0.00(0.42)$ & $-0.00(0.33)$ \\
Intercept & $0.09(0.89)$ & $0.01(0.98)$ \\
Number of Observations & 588 & 467 \\
R2 & 0.53 & 0.43 \\
Root MSE & 0.38 & 0.73 \\
\hline$* * * 99 \%$ significance level & $* * 95 \%$ significance level $* 90 \%$ significance level
\end{tabular}

Third, the renovated playground increased the level of social interactions. Fig. 10 (left) shows the Playground attendance breakdown by activity types. More people were babysitting or having a conversation after renovation. Fig. 10 (right) shows the attendance increase at the Playground by age group. The largest increase were the elderlies (55+), followed by young adults (18-55). Children usually played by themselves previously; after renovation, they were able to enjoy the company of parents or grandparents. 

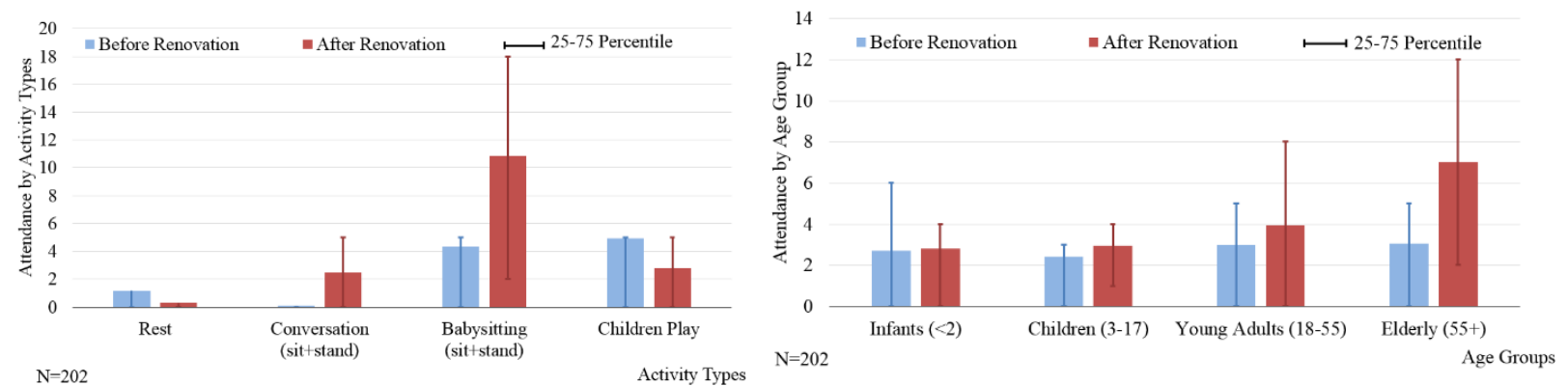

Fig. 10 (left) Playground attendance breakdown before and after renovation by activity types; (right) Playground attendance breakdown before and after renovation by age groups

Lastly, the experiment changed the playground's usage schedule in summer (Fig. 11). Before the renovation, most activities occurred in the early morning or evening; attendance remained low during the rest of the day. After the renovation, the majority of activities shifted to daytime hours. Similar phenomenon cannot be observed in moderate or cool seasons (Fig. 12) nor on 5 other sites (control group) (Fig. 13). Previously, occupants chose to use the playground before sunrise or after sunset to avoid excessive heat. There was no need to do so after renovation.

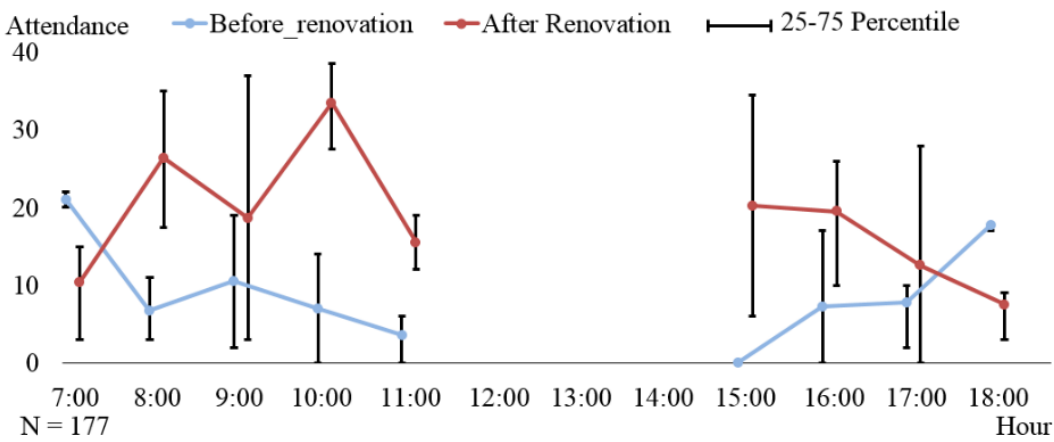

Fig. 11 Hourly attendance at the playground in hot season (June.-Sept)

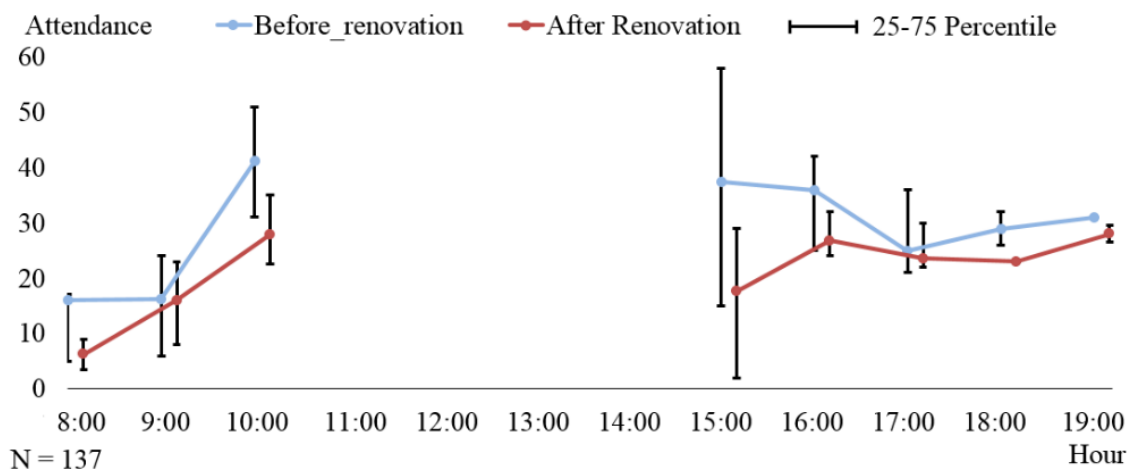

Fig. 12 Hourly attendance at the playground in moderate and cool seasons (Oct.-May) 


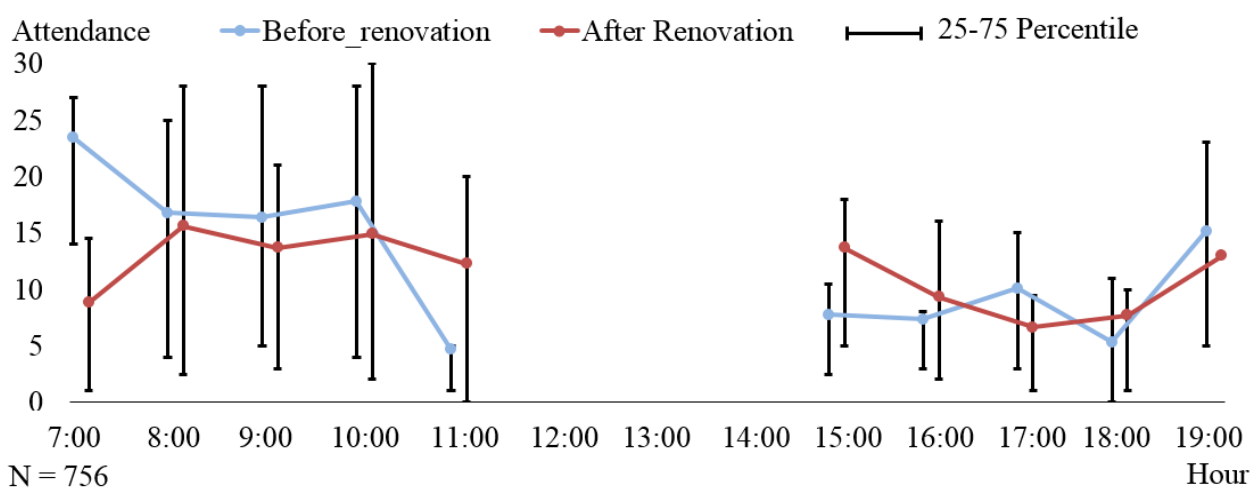

Fig. 13 Hourly attendance on 5 other sites (the control group) before and after the experiment in hot season (June.-Sept)

\subsection{Design Implications}

Findings from this study have implications for the design of open spaces. First, mitigation of summertime thermal stress is a design priority under humid subtropical climates. A more comfortable thermal environment brings behavioral benefits: open spaces are better attended; occupants stay longer, interact with each other, and are more likely to engage in intense activities. Design features such as shading shelters and vegetation cover were proved to be effective.

Second, an open space should designed with a thermal environment conducive to its intended activities and users. The space for intense spaces such as playgrounds, sports fields, cycling paths, and jogging trails, should maintain a cooler environment and avoid excessive heat stress. Spaces for light activities such as sitting or resting areas should stay closer to thermal comfort zone. OTE for Intense and light activities provides a reference for design. Senior exercise ground or multi-generational spaces should maintain a warmer thermal environment acceptable to the elderlies who were less tolerant to cold stress. OTE for the elderly can be a useful reference for design.

Third, open spaces with a diverse microclimate supports adaptive behaviors and can extend comfortable season for all. Individual occupants will have a good chance of finding a comfortable spot within their thermal acceptable range. This can be achieve by maximizing the combination of shading, vegetation cover, paving materials, and locations in relation to nearby buildings. An example can be found in the location adaptation observed across the 6 open spaces in this study (Fig. 14). The Tree Plaza, the Green Buffer and SD Square were popular in hot seasons because of shading and breeze. Most occupants stayed at the Playground and the Sunken Plaza in winter where they could enjoyed direct sunlight.

Although our renovation increased playground attendance in hot seasons, it acted in opposite ways in moderate and cool seasons. Certainly the shading and vegetation introduced by the renovation was unhelpful in cold days. Built with brick and mortar, our cities and open spaces rarely respond to seasonal fluctuation of the outdoor thermal environment. To create a lasting comfortable microclimate all year round, perhaps we need dynamic devices such as mobile shading, windbreak, combined with evaporative cooling, radiative cooling/heating devices that 
better respond to changing solar positions, temperature, wind, or humidity. New opportunities for research are opening up.

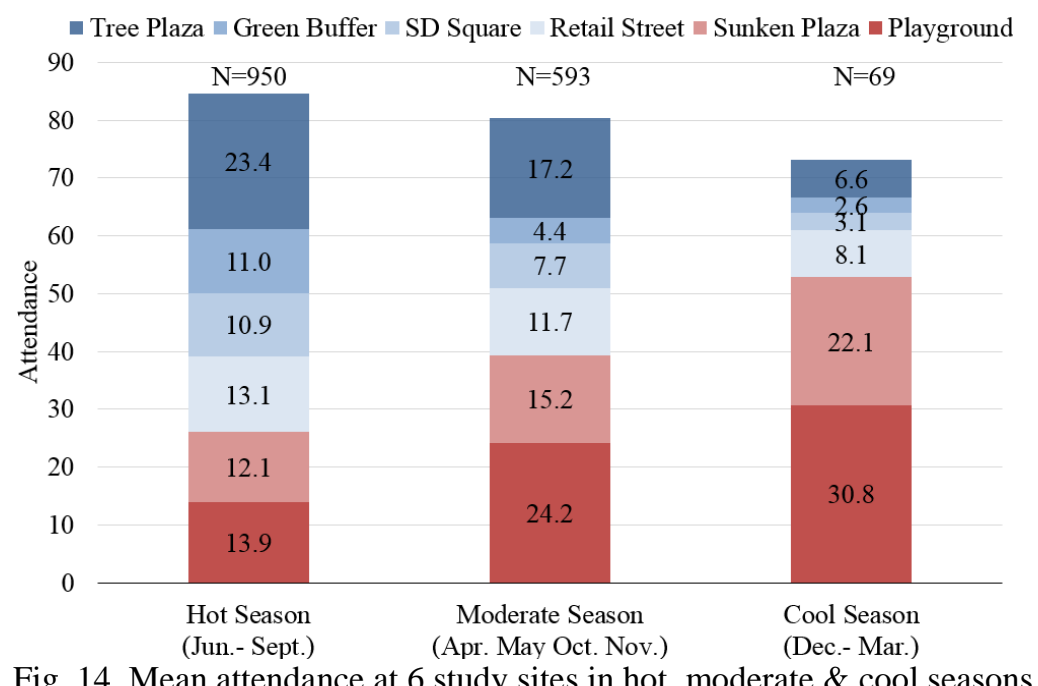

\section{Conclusion}

This paper presented an experiment study of outdoor activities conducted in humid subtropical climates. We developed the Optimum Thermal Environment (OTE) for outdoor activities based on attendance data. The OTE appeared to be a more consistent measure than the self-reported Thermal Acceptable Range (TAR) in this study. We also characterized behavioral responses to thermal environments by activity types, age and gender. Results showed that occupants were more likely to engage in intense activities in a cool environment, while more people performed moderate activities in warm and hot environments. The elderlies were less tolerant of cold stress compared with younger groups. Women preferred cooler environments compared with men. The renovated playground with reduced thermal stress become a more popular and socially interactive place: occupants stayed longer, reported less heat stress, and interacted with each other more often. We suggest that open spaces should be designed with a thermal environment conducive to its intended activities and target user groups.

\section{Acknowledgement}

Prof. Chunqiao Dong, Mr. Chao Zhang, and Mr. Qi Li of Huazhong University of Science and Technology, and Mr. Dayi Lai of Pudue University. The research is partially supported by Chengdu Vanke Co. and by the Francis Lau Research Fund of the University of Hong Kong. 


\section{Appendix 1}

\section{Outdoor Thermal Comfort Questionnaire}

Date:____ Time:___ Location:

1. Gender: (1) Male (2) Female

2. Age: (1) 6-12, (2) 12-18, (3) 18-40, (4) 40-65 (5) >65

3. Are you exposed in direct sunlight? (1) No / (2) Yes

4. Clothing (please tick the cloth combination you are wearing at this moment):

T-shirt (long-sleeve) / T-shirt (short-sleeve) / Shirt (long-sleeve) / Shirt (short-sleeve) / Pants / Shorts / Jacket

5. How long do you stay outdoors each day?

(1) <30mins (2) 30-60mins (3) 1-2 hours (4) >2 hours

6. How often will you come here each day? times/day

7. How long will you stay in this place each time?

(1) $<30$ mins (2) 30-60mins (3) 1-2 hours (4) >2 hours

8. Your activities have been mainly:

(1) Babysitting (sit), (2) Babysitting (stand), (3) Rest (4) Stroll, (5) Dance, (6) Chess \& Board Games, (7) Conversation (stand), (8) Conversation (sit), (9) Children's Play, (10) Exercise, (11) Picnic, (12) Others:

9. Please circle your current thermal sensation

\begin{tabular}{|l|l|l|l|l|l|l|}
\hline Hot & Warm & Slightly warm & Neutral & Slightly cool & Cool & Cold \\
\hline+3 & +2 & +1 & 0 & -1 & -2 & -3 \\
\hline
\end{tabular}

10. How do you describe the current thermal comfort conditions?

\begin{tabular}{|l|l|l|}
\hline (1) Uncomfortable & (2)Acceptable & (3)Comfortable \\
\hline
\end{tabular}

11. Please rank the most important factors for you to use an open space.

\begin{tabular}{|c|c|c|c|}
\hline shading & Aesthetic Qualities & Facilities & Safety \\
\hline & & & \\
\hline
\end{tabular}

12. Which aspect of thermal environment do you think should be improved on this site?

Thank you for your participation 


\section{Appendix 2}

We tested the statistical significance of the differences in OTE using the Chow Test (Partial F Test) (Chow 1960). The goal was to determine whether the coefficients for UTCI in a subgroup equal to those of other groups. The regression models for attendance and outdoor thermal environment is expressed through formula (A1) to (A3). The left-hand variable is mean attendance computed within 1 degree of UTCI bin $\left(\overline{\left.A_{\text {UTCI_btn }}\right)}\right.$; the right-hand variable is UTCI and $\mathrm{UTCI}^{2}$.

$$
\begin{aligned}
& \overline{A_{U T C I} b i n}=a U T C I^{2}+b U T C I+c+\varepsilon \quad \text { (A.1) for both groups } \\
& \overline{A_{U T C I-b i n}}=a_{1} U T C I^{2}+b_{1} U T C I+c_{1}+\varepsilon \quad \text { (A.2) for group } 1 \\
& \overline{A_{\text {UTCI_bln }}}=a_{1} U_{T C I^{2}}+b_{1} U T C I+c_{1}+\varepsilon \quad \text { (A.3) for group } 2
\end{aligned}
$$

We construct the null hypothesis that group 1 and group 2 attendances are equally affected by the outdoor thermal environment, thus $a_{1}=a_{2}, b_{1}=b_{2}$, and $c_{1}=c_{2}$. The formula for Chow Test Score can be expressed below

$$
F\left(k, N_{1}+N_{2}-2 k\right)=\frac{\left(S_{c}-S_{1}-S_{2}\right) / k}{\left(S_{1}+S_{2}\right) /\left(N_{1}+N_{2}-2 k\right)}
$$

where $S_{c}$ is the Sum of Squared Residuals from model (1). $S_{1}$ and $S_{2}$ are the Sum of Squared Residuals from group $1 \& 2$ accordingly. $k$ is the number of parameters in use ( 3 in this case). $N_{1}$ and $N_{2}$ are the numbers of observation for group $1 \& 2$. Using the male \& female groups as an example, the regression model of mean attendance and outdoor thermal environment for both genders can be written as:

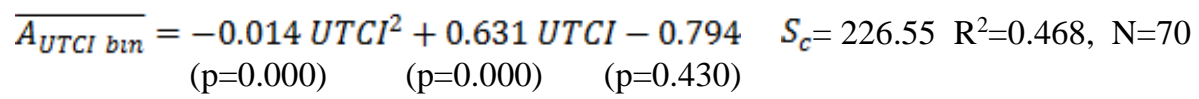

While for male group, the regression model for mean attendance can be written as

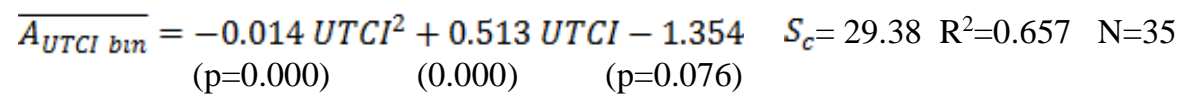

For female group, the regression model for mean attendance can be written as

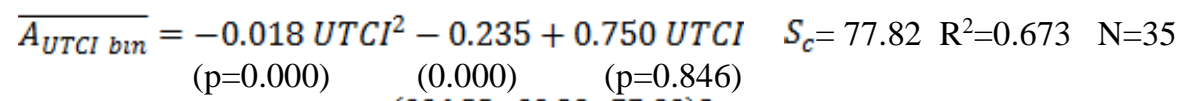

The Chow Test score $F=\frac{(226.55-29.38-77.82) 3}{(29.38+77.82) /(35+35-2 * 3)}=23.75$ with 64 degrees of freedom. After looking up the 0.05 critical value of the F-Distribution table, we reject the null hypothesis - the behavioral impact of outdoor thermal environment on male and female were significantly different. Chow Test scores between the age groups and types of activities are show in Table .

Table A.1 Chow-Test of Attendance between gender, age, and types of activities

$\begin{array}{ccccc}\text { Male : } & \text { Elderly: } & \text { Elderly: } & \text { Intense: Light } & \text { Intense: Moderate } \\ \text { Female } & \text { Young Adults } & \text { Children } & \text { Activities } & \text { Activities }\end{array}$




\begin{tabular}{lccccc}
\hline \# of Parameters $k$ & 3 & 3 & 3 & 3 & 3 \\
\hline $\begin{array}{l}\text { Degree of Freedom } \\
\left(k, N_{1}+N_{2}-2 k\right)\end{array}$ & $(3,64)$ & $(3,64)$ & $(3,64)$ & $(3,64)$ & $(3,64)$ \\
\hline Chow Test Score $F$ & 23.75 & 9.52 & 5.35 & 13.05 & 6.15 \\
\hline $\begin{array}{l}\text { Reject Null-Hypothesis } \\
(0.05 \text { critical value })\end{array}$ & Yes & Yes & Yes & Yes & Yes \\
\hline
\end{tabular}

\section{Appendix 3}

The model formula for attendance by activity types under various thermal environment is provided in Equation (A.5) below. The Mean Attendance $\left(\overline{A_{U T C I} \text { brn }}\right)$ was calculated within 1 degree of UTCI bin. The quadratic fitted equations were derived by regressing $\overline{A_{\text {UTCI }} \text { bin }}$ on $\mathrm{UTCI}$ and $\mathrm{UTCI}^{2}$.

$$
\overline{A_{U T C I \_b l n}}=a U T C I^{2}+b U T C I+c
$$

Table A.2 shows the results of OTE and quadratic fitted equations for various activity types. In general, the OTE for light and moderate activities covered the range of moderate and high temperature (UTCI scale). The OTE for intense activities fell in the range of lower temperature (UTCI scale). Revisions were made in the appendix due to the journal limit in number of tables allowed.

Table A.2. The Optimum Thermal Environment (OTE) and quadratic fitted model by activity types

\begin{tabular}{|c|c|c|c|}
\hline $\begin{array}{l}\text { Mean Attendance by } \\
\text { Activity Types* }\end{array}$ & $\begin{array}{l}\text { OTE in } \\
\text { UTCI I }{ }^{\circ} \mathrm{C}\end{array}$ & Quadratic Fitted Equation & $\mathrm{R}^{2}$ \\
\hline \multicolumn{4}{|c|}{ Light Activity (1.1-1.9 MET) } \\
\hline Rest (sit) & $14.2-28.2$ & $\overline{A_{\text {UTCI bun }}}=-0.003 \mathrm{UTCI}^{2}+0.138 \mathrm{UTCI}+0.129$ & 0.253 \\
\hline Board \& Card Games & $17.6-28.1$ & $\overline{A_{\text {UTCI bin }}}=-0.0004 \mathrm{UTCI}^{2}+0.020$ UTCI -0.105 & 0.126 \\
\hline Conversation (sit) & $12.1-30.6$ & $\overline{A_{\text {UTCI bin }}}=-0.001 \mathrm{UTCI}^{2}+0.030 \mathrm{UTCI}+0.284$ & 0.035 \\
\hline Babysitting (sit) & $15.0-28.4$ & $\overline{A_{U T C I} b r n}=-0.010 \mathrm{UTCI}^{2}+0.442 \mathrm{UTCI}-0.246$ & 0.378 \\
\hline Picnic & $17.8-28.1$ & $\overline{A_{\text {UTCI brn }}}=-0.002 \mathrm{UTCI}^{2}+0.095 \mathrm{UTCI}-0.537$ & 0.382 \\
\hline \multicolumn{4}{|c|}{ Moderate Activity (2.0-2.9 MET) } \\
\hline Conversation (stand) & 12.4-26.9 & $\overline{A_{\text {UTCI bin }}}=-0.002 \mathrm{UTCI}^{2}+0.072 \mathrm{UTCI}+0.264$ & 0.528 \\
\hline Babysitting (stand) & $18.5-30.8$ & $\overline{A_{\text {UTCI bin }}}=-0.009 \mathrm{UTCI}^{2}+0.437 \mathrm{UTCI}-2.073$ & 0.528 \\
\hline Stroll & $21.0-32.5$ & $\overline{A_{\text {UTCI bin }}}=-0.003 \mathrm{UTCI}^{2}+0.140 \mathrm{UTCI}-1.001$ & 0.244 \\
\hline \multicolumn{4}{|c|}{ Intense Activity (3.0+ MET) } \\
\hline Dance & $10.6-24.3$ & $\overline{A_{\text {UTCI bin }}}=-0.003 \mathrm{UTCI}^{2}+0.107 \mathrm{UTCI}+0.496$ & 0.174 \\
\hline Children Play & $11.9-25.4$ & $\overline{A_{\text {UTCI bin }}}=-0.005 \mathrm{UTCI}^{2}+0.181 \mathrm{UTCI}+0.520$ & 0.172 \\
\hline Exercise & $8.8-24.2$ & $\overline{A_{\text {UTCI brn }}}=-0.001 \mathrm{UTCI}^{2}+0.040 \mathrm{UTCI}+0.383$ & 0.142 \\
\hline All Activities & $15.2-28.8$ & $\overline{A_{\text {UTCI bin }}}=-0.037$ UTCI $^{2}+1.617$ UTCI -0.814 & 0.424 \\
\hline
\end{tabular}

* Observations in UTCI bins of $1,2,6,8,39,41,42,43{ }^{\circ} \mathrm{C}$ were removed because $\mathrm{N}<5$ 


\section{Reference}

ASHRAE, 2013. ASHRAE Standard 55-2013: Thermal environmental conditions for human occupancy, Atlanta, USA: American Society of Heating, Refrigerating and AirConditioning Engineers, Inc.

Blatteis, C.M., 2012. Age-Dependent Changes in Temperature Regulation \&\#150; A Mini Review. Gerontology, 58(4), pp.289-295. Available at: http://www.karger.com/doi/10.1159/000333148.

Blazejczyk, K. et al., 2012. Comparison of UTCI to selected thermal indices. International Journal of Biometeorology, 56(3), pp.515-535.

Brode, P. \& Wojtach, B., 2010. UTCI Calculator. Available at: http://www.utci.org/utcineu/utcineu.php [Accessed April 20, 2012].

Carmona, M. et al., 2003. Public places-urban spaces: the dimensions of urban design, Burlington: Architectural Press, Elsevier.

Chen, L. \& Ng, E., 2012. Outdoor thermal comfort and outdoor activities: A review of research in the past decade. Cities, 29(2), pp.118-125. Available at: http://www.sciencedirect.com/science/article/pii/S0264275111001053 [Accessed July 10, 2014].

Chow, G.C., 1960. Tests of Equality Between Sets of Coefficients in Two Linear Regressions. Econometrica, 28(3), pp.591-605. Available at:

http://www.jstor.org/stable/1910133\nhttp://www.jstor.org/stable/pdfplus/1910133.pdf?acce $\mathrm{ptTC}=$ true.

Cohen, P., Potchter, O. \& Matzarakis, A., 2013. Human thermal perception of Coastal Mediterranean outdoor urban environments. Applied Geography, 37, pp.1-10. Available at: http://www.sciencedirect.com/science/article/pii/S0143622812001142 [Accessed December $24,2015]$.

de Dear, R. \& Fountain, M., 1994. Field experiments on occupant comfort and office thermal environments in a hot-humid climate. ASHRAE Transactions: Research, (100), pp.457-474.

Égerházi, L.A., Kovács, A. \& Unger, J., 2013. Application of Microclimate Modelling and Onsite Survey in Planning Practice Related to an Urban Micro-Environment. Advances in Meteorology, 2013, pp.1-10. Available at: http://www.scopus.com/inward/record.url?eid=2-s2.0-84884860940\&partnerID=tZOtx3y1.

Eliasson, I. et al., 2007. Climate and behaviour in a Nordic city. Landscape and Urban Planning, 82(1-2), pp.72-84. Available at: http://www.sciencedirect.com/science/article/pii/S0169204607000473 [Accessed November $24,2015]$.

Gehl, J., 1987. Life Between Buildings: Using Public Spaces, Van Nostrand Reinhold. Heschong, L., 1979. Thermal delight in architecture, Cambridge, MA, USA: The MIT Press. Höppe, P., 1999. The physiological equivalent temperature - a universal index for the 
biometeorological assessment of the thermal environment. International journal of biometeorology, 43(2), pp.71-75.

Huang, J., Cedeño-Laurent, J.G. \& Spengler, J.D., 2014. CityComfort+: A simulation-based method for predicting mean radiant temperature in dense urban areas. Building and Environment, 80, pp.84-95.

Jendritzky, G., de Dear, R. \& Havenith, G., 2012. UTCI-Why another thermal index? International Journal of Biometeorology, 56(3), pp.421-428.

Lai, D. et al., 2014. Outdoor space quality: A field study in an urban residential community in central China. Energy and Buildings, 68, pp.713-720. Available at: http://www.sciencedirect.com/science/article/pii/S037877881300145X [Accessed October $28,2015]$.

Leisure and Cultural Services Department, 2006. Fitness Corners help foster healthy lifestyle among elderly,. Available at: http://www.lcsd.gov.hk/en/news/press_details.php?pd=20060130\&ps=04 [Accessed May 20, 2009].

Lin, T.P., 2009. Thermal perception, adaptation and attendance in a public square in hot and humid regions. Building and Environment, 44(10), pp.2017-2026. Available at: http://dx.doi.org/10.1016/j.buildenv.2009.02.004.

Matzarakis, A. \& Mayer, H., 1996. Another Kind of Environmental Stress: Thermal Stress, de Montigny, L., Ling, R. \& Zacharias, J., 2012. The Effects of Weather on Walking Rates in Nine Cities. Environment and Behavior, 44(6), pp.821-840.

Nikolopoulou, M. \& Lykoudis, S., 2006. Thermal comfort in outdoor urban spaces: Analysis across different European countries. Building and Environment, 41(11), pp.1455-1470. Available at: http://www.sciencedirect.com/science/article/pii/S0360132305002039 [Accessed October 20, 2015].

Niu, J. et al., 2015. A new method to assess spatial variations of outdoor thermal comfort: Onsite monitoring results and implications for precinct planning. Building and Environment, 91, pp.263-270. Available at: http://www.sciencedirect.com/science/article/pii/S0360132315000748 [Accessed August 26, 2015].

Parkinson, T. \& de Dear, R., 2015. Thermal pleasure in built environments: physiology of alliesthesia. Building Research \& Information, 43(3), pp.288-301. Available at: http://www.tandfonline.com/doi/abs/10.1080/09613218.2015.989662.

Pickup, J. \& de Dear, R., 2000. An Outdoor Thermal Comfort Index-Part I - The Model and its Assumptions. In R. de Dear et al., eds. Biometeorology and Urban Climatology at the Turn of the Millennium. WCASP 50: WMO/TD No.1026. Geneva: WMO, pp. 279-283.

Vanos, J.K., 2015. Children's health and vulnerability in outdoor microclimates: A comprehensive review. Environment international, 76, pp.1-15. Available at: http://www.sciencedirect.com/science/article/pii/S0160412014003511 [Accessed October 8, 2015]. 
Vanos, J.K. et al., 2016. Hot playgrounds and children's health: A multiscale analysis of surface temperatures in Arizona, USA. Landscape and Urban Planning, 146, pp.29-42. Available at: http://www.sciencedirect.com/science/article/pii/S0169204615002182 [Accessed December 9, 2015].

Whyte, W.H., 1980. The Social Life of Small Urban Spaces, New York: Project for Public Spaces.

World Health Organization, 2010. Global Recommendations on Physical Activity for Health, Available at: http://www.who.int/dietphysicalactivity/publications/9789241599979/en/.

Yang, W., Wong, N.H. \& Jusuf, S.K., 2013. Thermal comfort in outdoor urban spaces in Singapore. Building and Environment, 59, pp.426-435. Available at: http://www.sciencedirect.com/science/article/pii/S0360132312002508 [Accessed October 6, 2014].

Zacharias, J., 2004. Spatial Behavior in San Francisco's Plazas: The Effects of Microclimate, Other People, and Environmental Design. Environment and Behavior, 36(5), pp.638-658.

Zacharias, J., Stathopoulos, T. \& Wu, H., 2001. Microclimate and Downtown Open Space Activity. Environment and Behavior, 33(2), pp.296-315. 